\title{
APPLICATION OF DIGITAL STRUCTURE SIMULATION AS A TOOL FOR THE EXPLORATION OF WIDE SPAN STRUCTURE IDEAS
}

\author{
Shirley Wahadamaputera*), Bambang Subekti, Dian Duhita Permata
}

*) Corresponding author email : shirl@itenas.ac.id

Department of Architecture, Faculty of Architecture and Design, Institut Teknologi Nasional Bandung

\begin{tabular}{l}
$\qquad$ Abstract \\
\hline Article info \\
MODUL vol 21 no 2, issues period 2021 \\
\hline Doi $\quad: 10.14710 /$ mdl.21.2.2021.155-161 \\
Received $: 7$ december 2021 \\
Revised $: 20$ december 2021 \\
Accepted $: 30$ december 2021
\end{tabular}

Review on structure behaviour and visual appearance of a building is needed in generating creativity in the making of an architectural design. The use of any specific structure software will facilitate this in the process. This research aims to prove the effectiveness with which designers can compose alternative forms of architectural appearance through the use of the software. One of the tools in the creative process used in the exploration of 2dimensional frame structures is DR FRAME. The observations were carried in the Structure and Construction IV Studio at Itenas Architecture Study Program Bandung through a digital simulation using DR. FRAME software demo version. Several students are invited to explore various forms of wide-span truss structures at the level of unified integration. The results through the program execution show various diagrams which can be implemented in the design of the form and the type of structural components. DR.FRAME software enriches ideas in the wide-span structure design which provides an understanding of the relationship between structural behaviour and the appearance of architectural design. The use of other supporting software is supposed to be applied as an alternative search for various structural design ideas for architecture students.

Keywords: digital simulation; exploration; structural design

\section{INTRODUCTION}

Professional architect's approach in considering the structure in the design process varies from the approach structure as an aesthetic to structure that acts as a supporter of a form. A building's form adjustment done Shirley Wahadamaputera, Bambang Subekti, Dian Duhita Permata using building wrapping elements that differ from the structure's core design will result in extremely expensive construction costs. Designers are generally hesitant to intervene in the processing of structural forms, whereas engineers avoid complex calculations due to particular structural forms. Collaboration between architects and engineers to produce a good design is needed (Macdonald 2001). The architect was hesitant to intervene since they were having problems comprehending the logic of the wide-span structure and qualitatively examining the stability/stiffness of the structural design they created. Usually, to help understand this, architects conduct model studies, but model studies are not simple. The role of digital simulation can be helpful in making various alternative structural designs replace the usual models. The closest studio to observe the process of a designer doing architectural shape exploration is in an academic studio which applied Project Based Learning method.

The learning process in the Structure and Construction Studio IV introduces students to various structures on wide-span roofs. The course position in the curriculum map is to support the Architectural Design Studio in a wide-span building, which demands creativity in designing the work in the studio, teaching and delivering it. According to (Thomas, Jones, and Ottaway 2015), directed autonomous learning is learning in which students are guided by curriculum topic, coaching, and assessment; they are supported by tutors and the learning environment; and they practice, either independently or in cooperation with peers. Freedom in creativity is a result of mastery of structural logic. The learning process is also unique, creation does not come from just hearing or seeing other people do it, but the best result is to do it yourself (Thomas, L., Hockings, C., Ottaway, J., and Jones 2015) found that new university students did not have a clear perception of what independent learning was or how to do it. Students regarding direction and guidance from their tutors. However, when students moved towards independence, they received more information and learnt more from their peers.

Various learning strategies were used to explore roof shape, including group work, sketching, and small 
models. The epidemic changes the learning model to a virtual domain, which has accidentally turned out to be a boon for digital era learning. When students believe that the Structure and Construction studio is only about mathematical calculations, then challenges occur. The teacher must create a digital learning paradigm which is appropriate for the class. The accessible digital apps range in complexity from easy to difficult, and students select the most mastered based on the amount of time they have to complete the assignment.

The aim of this research is to see how effective it is to use software to identify alternate interpretations of the architectural shape of a wide-span building's roof which correspond to structural logic principles. The objective of this study is to know how understanding structural principles helps students explore architectural ideas, the process of using the software to find architectural shapes and after using simulation software, students' opinions. Therefore observations will be limited to the active vector system group with the demo version of the DR.FRAME software. This software can help create a 2-dimensional simulation of a structural model, both the frame structure of a high-rise building or a widespan truss structure. The findings of effectiveness in this observation will encourage students to use the software. It also facilitates the search for roof shapes that meets the logical aspects of structural design (Schueller 1983).

\section{RESEARCH METHOD}

This study uses qualitative approaches. Figure 1 shows that the research steps begin with collecting sample data for the active vector roof structure system drawing in 2D form. Data was obtained from 7 students and image data was collected through the shared google drive system. Before and after students make simulations, students are asked to fill out a questionnaire to measure their initial understanding of the theory of loads, reactions, forces, and differences in various wide-span structural systems (Figure 1).

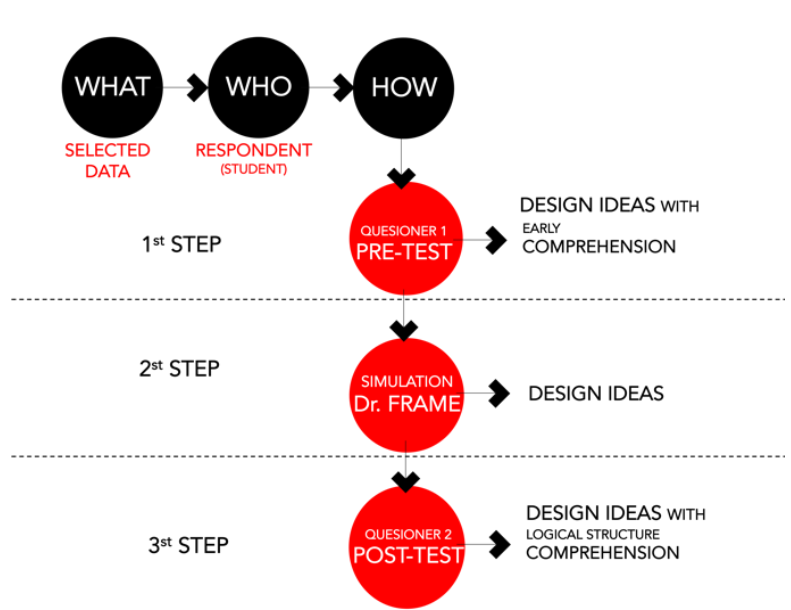

Figure 1. Steps of research activities

\section{RESULT AND DISCUSSION}

\section{Pre-simulation Test: Basic Logic structure understanding}

The basic understanding of the Vector Active wide-span structure system includes understanding loads and forces, differences in frames and trusses, and the behavior of loads and forces on structures, members, and supports they have obtained is very necessary in the testing process through the DR FRAME software simulation. This understanding is tested qualitatively through their opinions on the statements about the logic of the structure.

Pre-simulation questionnaires with closed questions about theory of loads, wide-span structures system and support system were used to collect data. The questionnaire contains multiple choices on a Likert scale, namely strongly agree, agree, undecided, disagree, and strongly disagree (Figure 2). Respondents are not free to give answers and opinions in a closed questionnaire because respondents choose to provide answers (Surahman, Rachmat, Mochamad, Supardi 2016).

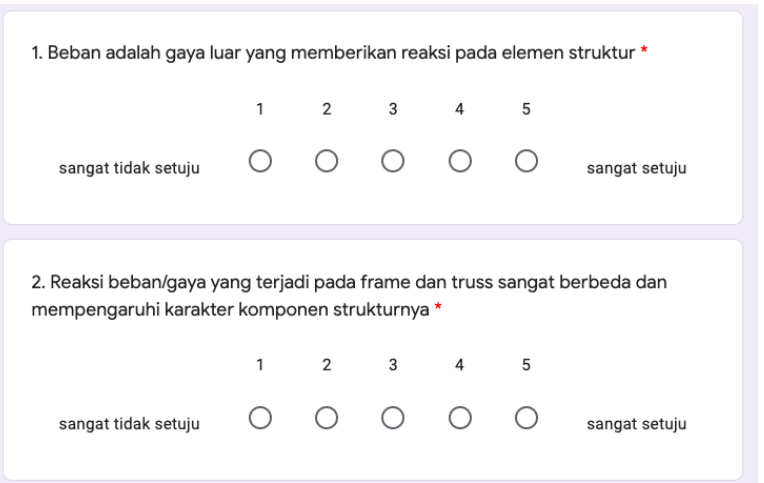

Figure 2. Pre simulation questionnaire form 
The results of the pretest respondents generally understood the rules of the structure being asked, although only $30 \%$ were very confident in their opinions (Figure 3).

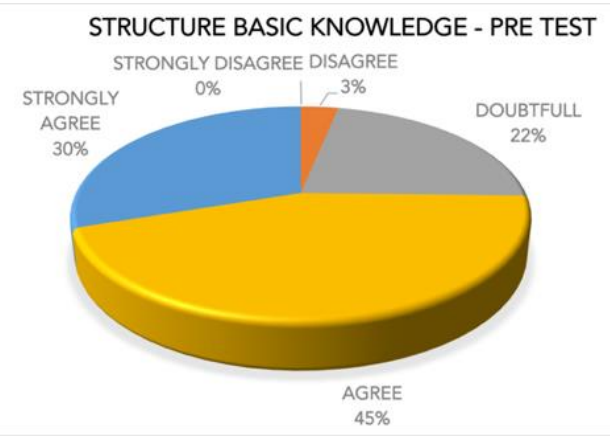

Figure 3. Structure Basic knowledge pre-simulation questionnaire results

\section{Simulation Process: Ideas exploration through DR FRAME software}

The next step is to continue the study by conducting a simulation using DR.FRAME software to the works of the students as a case study (Harahap 2020), and measuring the result to obtain an overview of the number of design ideas produced per student.

\subsection{Data selection}

The classification of the structure employed in this study is Heino Engel's (Engel 1997), namely the Vector active structure system, since it is the most frequently utilized method in other architectural design studios. The choice of software is considered against the ability to analyse frames and truss, in the vector active structure group. The structural designs created by the participants were chosen based on the simulation capabilities of the DR.FRAME program, and seven designs were chosen as study objects (Table 1). According to (Cowan 1981), the mechanism of a structure may be investigated at two levels: the truss as a whole (in bending), or individual components of the truss (in tension or compression).
Table 1. The structural design of respondents

\begin{tabular}{l|l|}
\hline $\begin{array}{l}\text { IDENTITY } \\
\text { NUMBER }\end{array}$ & $\begin{array}{c}\text { RESPONDENT'S } \\
\text { NAMEE }\end{array}$ \\
\hline 212019022 & ARANCAS \\
\hline 212019029 & $\begin{array}{c}\text { IINUL } \\
\text { JAMAL }\end{array}$ \\
\hline 212019077 & $\begin{array}{c}\text { DWIRUCTURE DESIGN } \\
\text { ADI SUKMA }\end{array}$ \\
\hline 212019078 & $\begin{array}{c}\text { M. ELDY FAJRI } \\
\text { ABDURRAHMAN }\end{array}$ \\
\hline 212019098 & $\begin{array}{c}\text { M. FUROAN FAHD } \\
\text { OSCAR }\end{array}$ \\
\hline 212019120 & \begin{tabular}{c} 
ARMALIFYA PUTRI \\
\hline
\end{tabular} \\
\hline
\end{tabular}

The design of the wide-span structure chosen by 7 respondents was different: 2 respondents chose a trussed arch structure (Armalifya Putri and M. Furqon Fahd Oscar), 2 respondents chose a trussed system (Dwi Adi Sukma and M.Eldy Fajri Abdurrahman), 1 respondent chose trussed frame structure (Ainul Jamal), 1 respondent chose biaxial intersection trusses structure (Arancas), and 1 respondent chose parallel chord trusses (M. Fauzan Amir).

\subsection{DR. FRAME structure software}

DR. FRAME implements a rich direct manipulation environment in which users can interactively build and test 2-D truss and frame structures while receiving visual and numeric feedback to indicate structural behaviour (Figure 4).

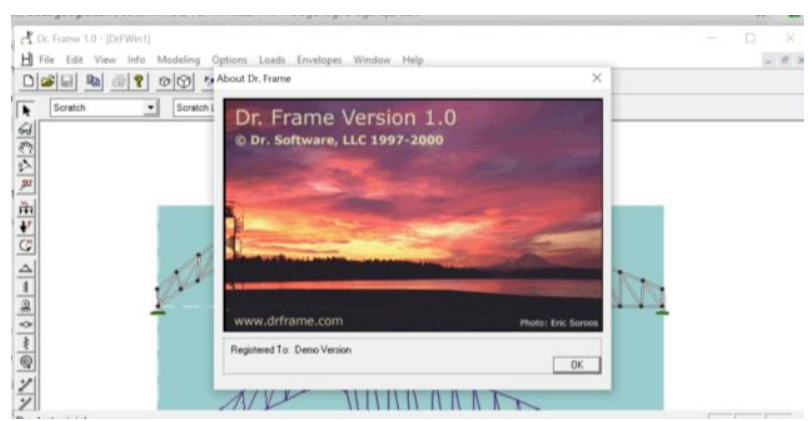

Figure 4. Software DR. FRAME version 1.0 (https://dr-frame-demo.software.informer.com/ access 10 September 2021) 
Students in the Structure and Construction Studio IV coursework utilize the software's ability to display structure behaviour to explore several structure design ideas following the steps as seen in Figure 5.

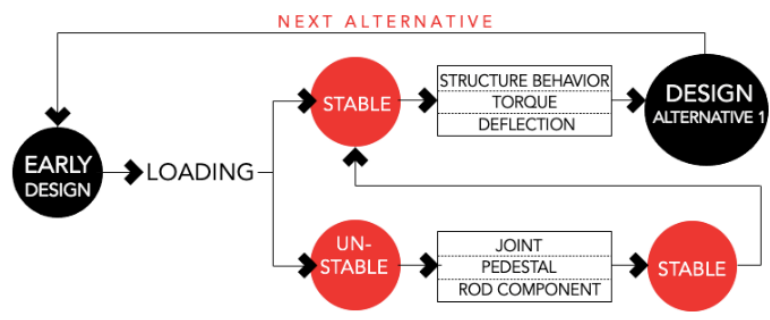

Figure 5. DR.FRAME software simulation steps chart

\subsection{Simulation process}

Participants in the Structure and Construction IV course are given 2 (two) alternative plans of 46,9 meter and 40,5 meter. Roof spans over than $12 \mathrm{~m}$, based on the most recent (R. Chudley, R. Greeno 2020), in Building Construction Handbook, and (E. Allen 1995) in The Architect's Studio Companion p 103, fall under the wide - span group. 47 participants use the active vector structure system to create designs. Only the flat truss and curve truss in active vector systems could be supported by the DR. FRAME software. Four students were chosen to represent four group types exploration from a group of 47.

Respondents took part in all aspects of the research. According to the flow diagram in figure 4 respondents create the original design, and then the shape is adjusted using the auto truss command on the modelling command. Afterwards, a basic loading (vertical force) was applied. If the result is stable, the respondent may learn more about the structure's type, the amount of the moments, forces, and the structure's deflection. If the structure's outcome is unstable, the respondent processes the joint, the type of support, and the rod's arrangement/pattern. The stability of the frame structure can be achieved in two ways: diagonal bracing or stiff joints(chord) arrangement (Schodek and Bechthold 2014). The software performs structural stability analysis immediately, allowing design options to be created right away.

In Figure 6 display, alternative 01 is the first iteration, which is a 2-hinged arch structure with pinned joint and roller support. Alternative 02 is obtained by changing the 2-hinged arch structure to a 3-hinged arch, but the structure becomes unstable. The solution is to replace the roller support into a pinned support. Alternative 03 is a modification of alternative 02 .
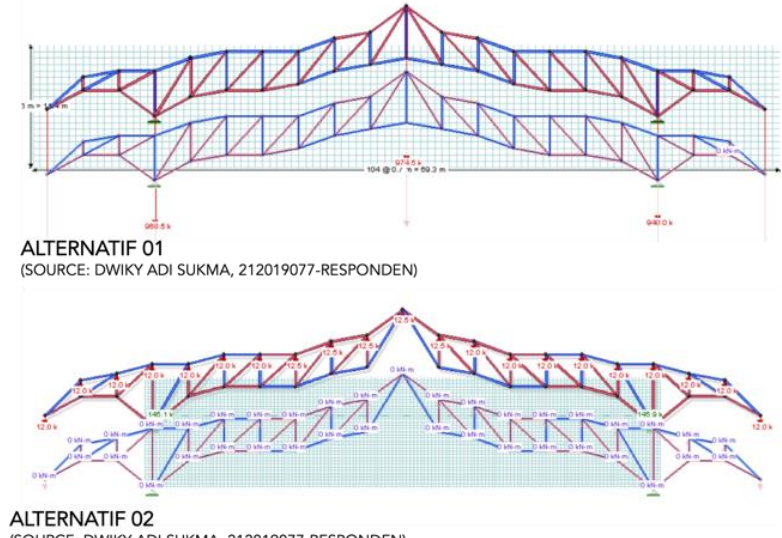

(SOURCE: DWIKY ADI SUKMA, 212019077-RESPONDEN)

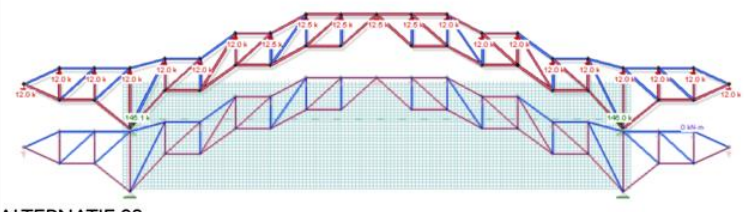

ALTERNATIF 03

(SOURCE: DWIKY ADI SUKMA, 212019077-RESPONDEN)

Figure 6. Exploration of Dwiki Adi Sukma represents group type 1 (Sukma, 2021)

Arancas was simply trying to see the effect of changing the joint in the middle of the stretch and changing from a rigid joint to a pinned joint. From alternative image 1, it appears that the structure is unstable. This happens because the support is still using pinned support and roller support. Efforts are made to add a rod in the middle, so that the structure becomes stable (Figure 7).

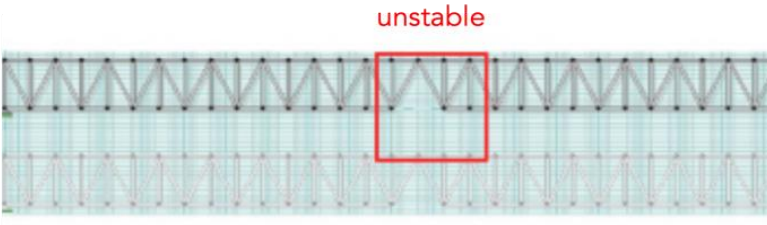

ALTERNATIF 01

(SOURCE: ARANCAS, 212019022-RESPONDEN)

Adding horizontal rods

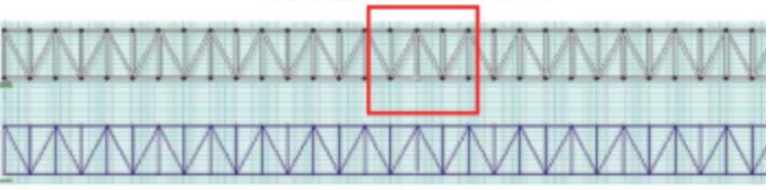

ALTERNATIF 02

(SOURCE: ARANCAS, 212019022-RESPONDEN)

Figure 5. Exploration of Arancas represents group type 2 (Arancas, 2021) 
Armilifya developed a curve truss structure with joint support (2-joint arch). Alternative design is done by changing the direction of the diagonal rods and adding the rods (Figure 8).

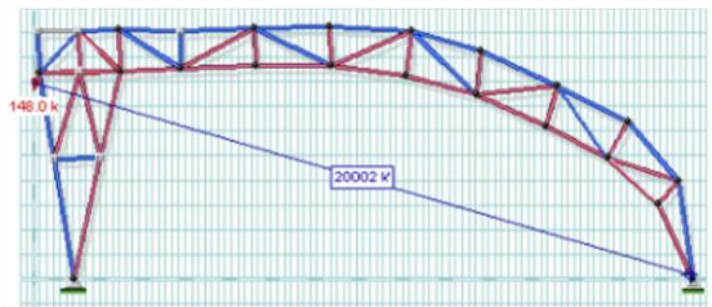

ALTERNATIF 01

(SOURCE: ARMALIFYA, 212019120-RESPONDEN)

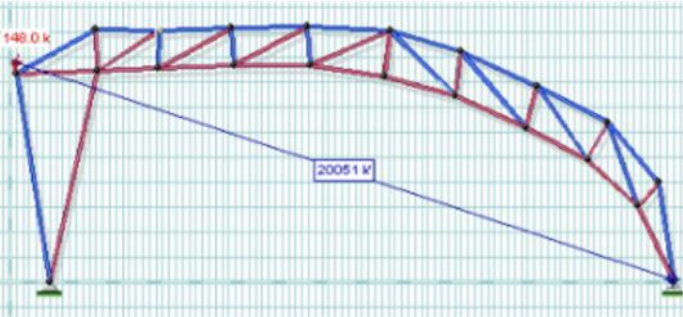

ALTERNATIF 02

(SOURCE: ARMALIFYA, 212019120-RESPONDEN)

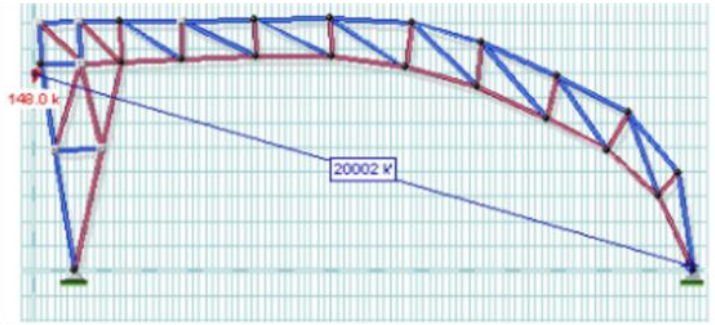

ALTERNATIF 03

(SOURCE: ARMALIFYA, 212019120-RESPONDEN)

Figure 8. Exploration of Armalifya Putri represents group type 3 (Putri 2021)

In a study conducted by Fauzan Amir, the structure was tested by changing the type of support. Alternative 1 shows a structural system using pinned support, while alternative 02 shows a structural system using pinned support and roller support. The difference between tensile and compression rods can be seen in the two figures. Alternative image 02 shows the tension rod is quite dominant. The outer curvature is dominated by the compression member, while the inner curvature is dominated by the tension member. In alternative 03 vertical bars are removed and use pinned support. The two diagonal bars in the centre of the force are zero. In this Fauzan exploration, it can be learned how the changes in the pedestal (Figure 9).

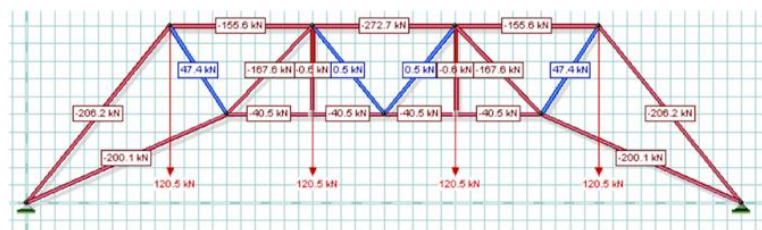

ALTERNATIF 01

(SOURCE: M. FAUZAN AMIR, 212019137-RESPONDEN)

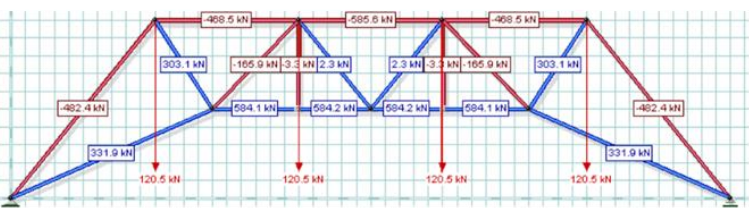

ALTERNATIF 02

(SOURCE: M. FAUZAN AMIR, 212019137-RESPONDEN)

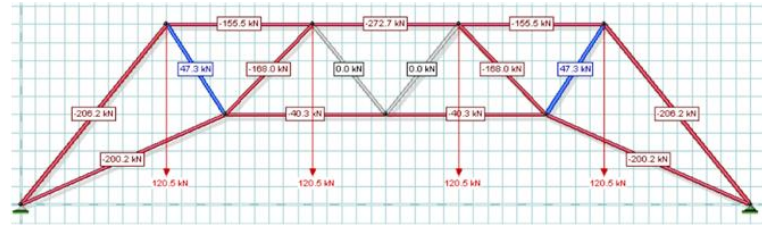

ALTERNATIF 03

(SOURCE: M. FAUZAN AMIR, 212019137-RESPONDEN)

Figure 9. Exploration of Fauzan Amir represents group type 4 (Amir, 2021)

After the simulation using the DR.FRAME software, each respondent found alternative designs of structures with varying numbers, 1 to 7 alternatives (Table 2).

Table 2. Number alternatives design per-respondent

$\begin{array}{ccc}\text { IDENTITY } & \text { RESPONDENT'S } & \text { NUMBER OF } \\ \text { NUMBER } & \text { NAME } & \text { DESIGN ALTERNATIVE }\end{array}$

\begin{tabular}{l|c|c}
212019022 & ARANCAS & 2 \\
\hline 212019029 & $\begin{array}{c}\text { AINUL } \\
\text { JAMAL }\end{array}$ & 1 \\
\hline 212019077 & $\begin{array}{c}\text { DWIKI } \\
\text { ADI SUKMA }\end{array}$ & 3 \\
\hline 212019078 & $\begin{array}{c}\text { M. ELDY FAJRI } \\
\text { ABDURRAHMAN }\end{array}$ & 6 \\
\hline 212019098 & $\begin{array}{c}\text { M. FURQAN FAHD } \\
\text { OSCAR }\end{array}$ & 4 \\
\hline 212019120 & $\begin{array}{c}\text { ARMALIFYA PUTRI } \\
212019137\end{array}$ & M. FAUZAN AMIR \\
\hline
\end{tabular}

In particular, DR. FRAME as a digital simulation software is very helpful for respondents in solving widespan flat or curved truss design problems, both in an effort to understand the behaviour of the structure as well as in producing structural design ideas. Direct execution of the software appears visually in graphical form, making it very easy for respondents (architects) to understand the behaviour of the structure. 


\section{Post Simulation Test: User's opinion}

Users of digital software can determine how much shape exploration is carried out by utilizing digital simulations. The search for forms can be stopped in the second simulation because the ideas are considered as expected.

The measurement of the effectiveness of software used as a structural design tool should be strengthened by the responses of the software users through questionnaires. Post-simulation questionnaires with closed questions were used to collect data and meant to provoke student feedback on the effectiveness of software's use.

Respondents' answers regarding the use of this software in assisting the production of design ideas indicate that almost all respondents strongly agree.Figure 10 (a).

Figure 10 (b) shows the ease of use (userfriendliness) of the software. While in Figure 10 (c) visualisation of the software can greatly assist in the process of creating a variety of structural designs.

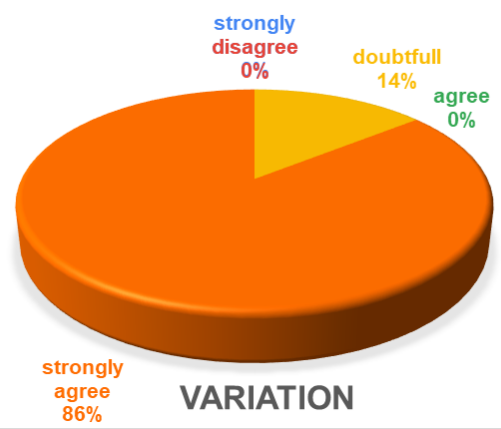

(a) DR. FRAME software questionnaire result on design ideas variation aspect

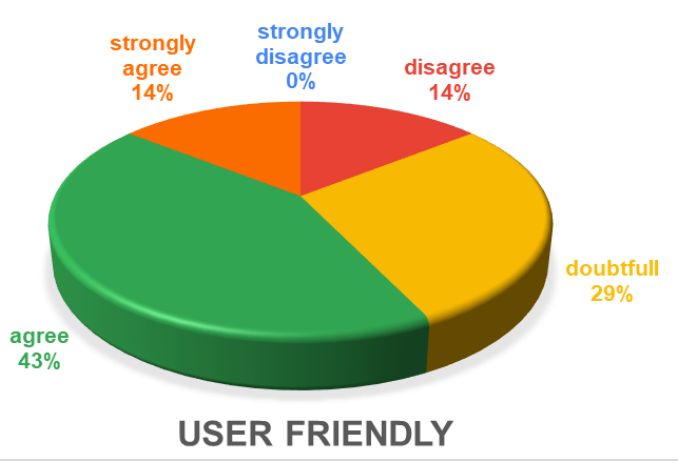

(b) DR. FRAME software questionnaire result on user friendly aspect

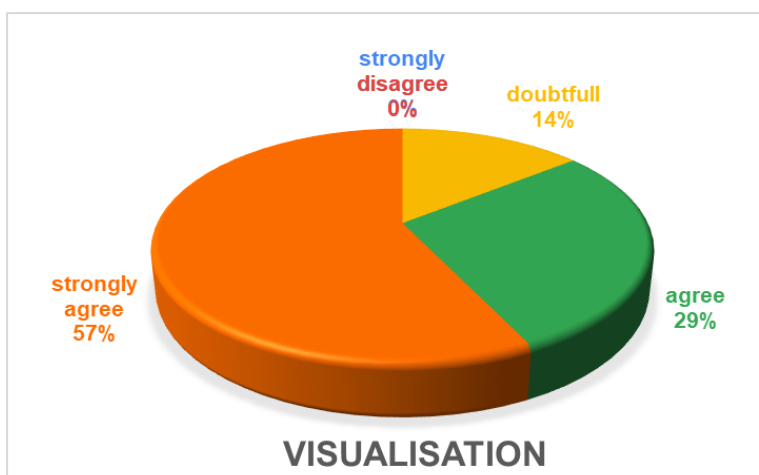

(c) DR. FRAME software questionnaire result on visualisation aspect

Figure 10. DR. FRAME software questionnaire result on variation, user friendly, and visualisation aspect

Respondents stated that the DR. FRAME software was very effective in producing designs and understanding structures, such as:

- easy to know load reaction

- know the stability of the structure

- help design structure

- easy to understand load distribution and the effect of support and joint types

- helps generate structural variations of wide-span design

This shows that the use of software as a tool for exploring design ideas is effective in coming up with various ideas that meet the logical structure.

The difference in the initial student level of understanding before and after conducting the simulation was measured based on data from the second questionnaire.

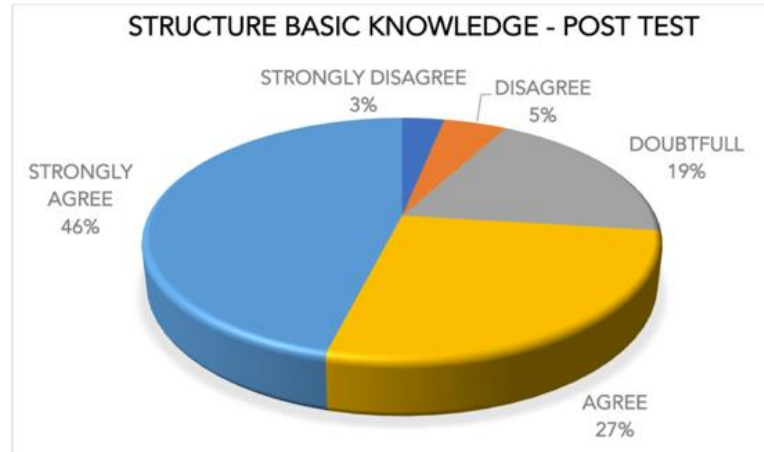

Figure 11. Structure Basic knowledge post simulation questionnaire results

The results of the questionnaire regarding the basic knowledge of the structure during the postsimulation questionnaire showed an increase in opinion (answers) strongly agree with an increase of $16 \%$ from 
the results of the pre-simulation questionnaire. This shows that the understanding of the respondents' basic knowledge has increased after doing a simulation using the DR.FRAME software (Figure 11).

On the other hand, the use of this software is complained about because of the limitations of the demo version, which suddenly crashes or force closes and cannot be saved.

The results obtained through the simulation show that the use of software allows one to search for several structure design ideas, as well as that, at the same time, the logic of the structure is achieved.

\section{CONCLUSION}

The use of software as a tool to assist designers in their design exploration will continue to grow. Software accelerates the process of identifying alternative designs that meet logical structure. The introduction of its utilization will offer individuals confidence when joining the realm of multi-disciplined jobs. Its use will accelerate new and improved inventions and is highly awaited by architects.

Utilization of software as material for further research is possible to provide various opportunities for architects to change the dimensions of components, replace and combine materials used, explore efficient structural forms, etc.

\section{Acknowledgement}

All research results associated with this research are part of the learning process in The Structure and Construction Studio IV and other research conducted by the authors. The authors are also grateful to the students who have fully participated in the process of simulation.

\section{REFERENCE}

Cowan, Henry J (1981) Structural Systems. New York: Van Nostrand Reinhold Company.

E. Allen, J. Iano (1995) The Architect's Studio Companion. 2nd ed. New York: John Wiley \& Sons.

Engel, Heino (1997) Structure System. Deutschland: Hatje Cantz Verlag.

Harahap, Nursapiah (2020) Penelitian Kualitatif. 1st ed. edited by H. Sazali. Medan: Wal ashri Publishing.

Macdonald, Angus J (2001) Structure and Architecture. second. edited by A. Press. Oxford: Architecture Press.

R. Chudley, R. Greeno, K. Kovac (2020) Chudley and Greeno's Building Construction Handbook. twelve. Ney York: Routledge.

Schodek, Daniel L., and Martin Bechthold (2014) Structures. New Jersey: Pearson Eduvation, Inc.

Schueller, W. n.d. Spanning Space, Horizontal Span Building Structures.
Surahman, Rachmat, Mochamad, Supardi, Sudibyo (2016) Metodologi Penelitian. Jakarta.

Thomas, L., Hockings, C., Ottaway, J., and Jones, R. (2015) Independent Learning: Student Perspectives and Experiences.

Thomas, Liz, Robert Jones, and James Ottaway (2015) Effective Practice in the Design of Directed Independent Learning Opportunities Summary of the Main Research Report. York. 